\title{
Diversified Case Teaching of Automatic Control Principle
}

\author{
Du Yanhong \\ College of Engineering and Technology \\ Tianjin Agricultural University \\ Tianjin, China \\ yanhong_du@163.com \\ Wang Li \\ College of Engineering and Technology \\ Tianjin Agricultural University \\ Tianjin, China \\ 503581900@qq.com
}

\author{
Yang Renjie \\ College of Engineering and Technology \\ Tianjin Agricultural University \\ Tianjin, China \\ rjyang1978@163.com
}

\author{
HU Xishuan \\ Sinoma Energy Conservation Ltd \\ Tianjin, China \\ 38358142@qq.com
}

\begin{abstract}
Automatic Control Principle is a strong theory course. The diversified case teaching method is introduced into the course, including multiple teaching materials such as course ware, video and experiment. According to the existence of strong theory, complex formulas, complicated mathematical derivation and difficulty of combining theory with practice in automatic control theory, the case is applied progressively throughout the whole teaching process, and it fully stimulates the enthusiasm and initiative of the students, helps students to understand theore tical knowle dge, actives classroom atmosphere, cultivates the students' awareness of communication and cooperation, improves the students' creative ability and makes the connection between theory and actual ability. It obtained good te aching effect.
\end{abstract}

Keywords-Automatic Control Principle, Case Teaching, Diversified, Teaching Effect

\section{INTRODUCTION}

The "Automatic Control Principle" is a course offered by many engineering colleges in China, involving traditional majors such as control, electrical, mechanical, communication, instrumentation and energy and power [1]. The curriculum is theoretically strong and involves many aspects of mathematical knowledge with a certain depth and difficulty. Traditional teaching methods centered on teachers and teaching materials. They focus on normativeness and neglect innovation. In most of the classroom teachers speak, the students listen, the teacher writes the student's notes, the teacher asks the students to answer, the teacher is the imparter of knowledge, and the student is passive recipients of knowledge. . Although teachers' teaching logic is strict, students are not targeted in the learning process, their purpose is not clear, they are boring, and lose their initiative and enthusiasm for learning, and classroom efficiency is low [2, 3] Case teaching method is contrary to traditional teaching methods. It upholds the modern teaching philosophy, strengthens the overall, generative, continuous and humanistic

1. Innovation and Entrepreneurship Training Reform Model Project of Tianjin Agricultural University (20170812)

2. Education and Teaching Reform Project of Tianjin Agricultural University (2016-B-08) teaching objectives. It focuses on the mastery of students' knowledge and skills and the opening of intelligence. It also pays more attention to the attitude and value of cultivating, encourages and emphasizes students' individualized understanding of cases, highlights the cultivation of doubt, criticism, innovation spirit and practical ability. The theory is recreated through specific examples, which is transformed into concrete and simplification of the complex issues. The students proceed from specific problems, seek solutions to the problems through the analysis and thinking, explore the rationality and scientificity of the method, and finally reach an more concrete and profound understanding of the abstract theory[4-6].

\section{EDUCATION CONCEPT OF CASE TEACHING}

The basic education concept in the 21st century is 'to focus on the development of students and to focus on cultivating a new generation of people's sense of responsibility, self-cooperative learning ability, living ability, scientific spirit, innovation awareness, and creative ability." The principle of automatic control principle is a very important professional basic course for the measurement technology \& instrumentation major and electrical \& automation majors in our school. It is the basis for follow-up professional courses, and the quality of teaching directly affects the teaching results of subsequent professional courses; at the same time, the course is also the written test professional courses for many colleges and universities to take master's recruitment, and is the basis for graduate students to study professional courses, so the automatic control principle has a very important position whether in undergraduate teaching, or in graduate teaching. For the problems of strong theory, complex formulas, complicated mathematics derivation, difficult combination of theory and practice, and based on my more than ten years of teaching experience, I introduced case teaching in classroom teaching, and established a student-centered education and teaching concept, focusing on students. The teaching design is based on the familiar cases of students and puts the knowledge 
of the curriculum into practice. it also from shallow to deep, from simplicity to complex, from the local to the whole, discusses system analysis and design process, develops students' ideas, and cultivates students' autonomy creativity, and systematicness in the learning process, stimulates students' reflective awareness and innovative spirit, and improves students' comprehensive ability and quality.

\section{THE SELECTION OF CASES}

"The automatic control principle" is a theoretical foundation course with a strong theoretical basis for engineering. How to make the theoretical knowledge be applied is worth considering[7]. Based on the characteristics of the students, we introduced a wide range of teaching materials such as courseware, videos, and experiments and two types of cases into the classroom for different knowledge points are introduced. It gradually penetrates through the entire teaching process, inspires students' interest in learning and achieves good teaching. effect.

\section{A. Teaching Cases of Course System}

Such cases shall be interesting and familiar to the students. The teaching cases of "people taking things" is set up, which deduces the control concepts of the process of detecting deviations, correcting deviations of the automatic control system, and also deduces the learning objectives and tasks of the courses: the composition, analysis and design of control system.

According to the objectives and tasks of curriculum, mainline of a "System Mathematical Model-System AnalysisSystem Integrated Design” is formulated, as shown in Fig. 1. The mathematical model of the control system is the mathematical expression of the description system, and the premise and basis for solving the control problem. The system analysis is the premise of the system's comprehensive design, and also the focus of the teaching. Circumjacent of three factors of stability, accuracy and rapidity, it mainly discusses the method of time domain analysis, root locus, frequency domain response; The ultimate goal of learning is system synthesis design.

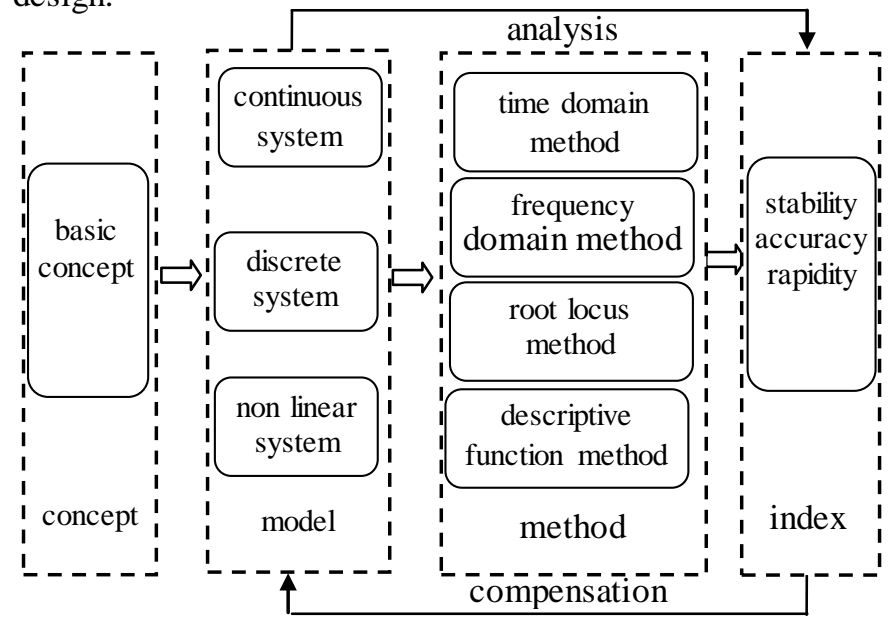

Fig. 1. The main line of theoretical knowledge
The main thread of this course is to link knowledge points together, enhance the rationality and logic of explanation, so that students grasp the basic concepts, theories, and applications of control principles within a limited hours.

The case aims to derive the learning ideas, tasks, and goals of this course through a typical example. It also shows the various knowledge points in the automatic control principle to reveal the interrelationships among the various knowledge points so that students can clearly define the task, focus and difficulties of the course, effectively link the before and after knowledge, and learn handily.

\section{B. Interpretation of Diversified Teaching Cases of Theoretical Knowledge}

Such cases shall have an intuitive effect on one single complex knowledge point, and cover most of the knowledge points of the course on comprehensive knowledge points, and have certain depth and difficulty based on a certain degree of comprehensiveness. According to the needs of a section of teaching objectives and content, combined with the requirements of the syllabus, a number of separate cases such as inverted pendulum, displacement system, liquid level system, speed control system, etc. are carefully selected. The mastery and understanding of discrete knowledge points have been improved through the interpreter of a case to explain a knowledge point. In organizing teaching, one or two specific system design are taken as the center to organize teaching, and several gradual cases are selected according to the requirements of system design, finally the teaching of comprehensive knowledge points is organized through each case. According to the characteristics of the automatic control principle course and the experience of many years of teaching, motor speed control system which the students are familiar with is selected during the teaching process, and in the system analysis, the design process a number of typical cases are matched.

The model is established by students as per the learned circuit and physics knowledge throughout the entire teaching process, and simplified models are obtained through simplified. During the analysis of time domain of the system, the MATLAB experiment simulation of the control system is used to observe the response of the system, and the an intuitive understanding of concept is achieved. Based on this, the concept is explained and the influencing factors of the performance are analyzed. During the analysis of the frequency domain and the root locus, the same method is used to guide students to learn and explore on the basis of intuitive understanding. During the design of the control system, the design indicators is set, so that students can explore solution based on existing knowledge, and verify the program. design the controller, and then the students enter the verification and new one round exploration phase.

The case teaching aims to reproduce the theory through specific cases, transform the abstract the specific, simplify the complex issues, stimulate the students' enthusiasm for learning, enable the students to proceed from specific problems, seek solutions for the problems through the analysis and reflection, and explore the rationality and scientificility of the methods, 
and ultimately achieve a more concrete and profound understanding of abstract theories, which will benefit students in their future study and work.

\section{METHODS AND MEASURES}

In order to make better use of diversified case teaching, such principles are followed that a gradual and orderly manner, gradually improving each other, gradually improving the point-to-face approach, opening up the curriculum system, and reflecting the principle of curriculum knowledge. The four aspects of conducting courseware production, classroom lectures, simulation experiments, and physical objects have been done, as shown in Fig. 2.

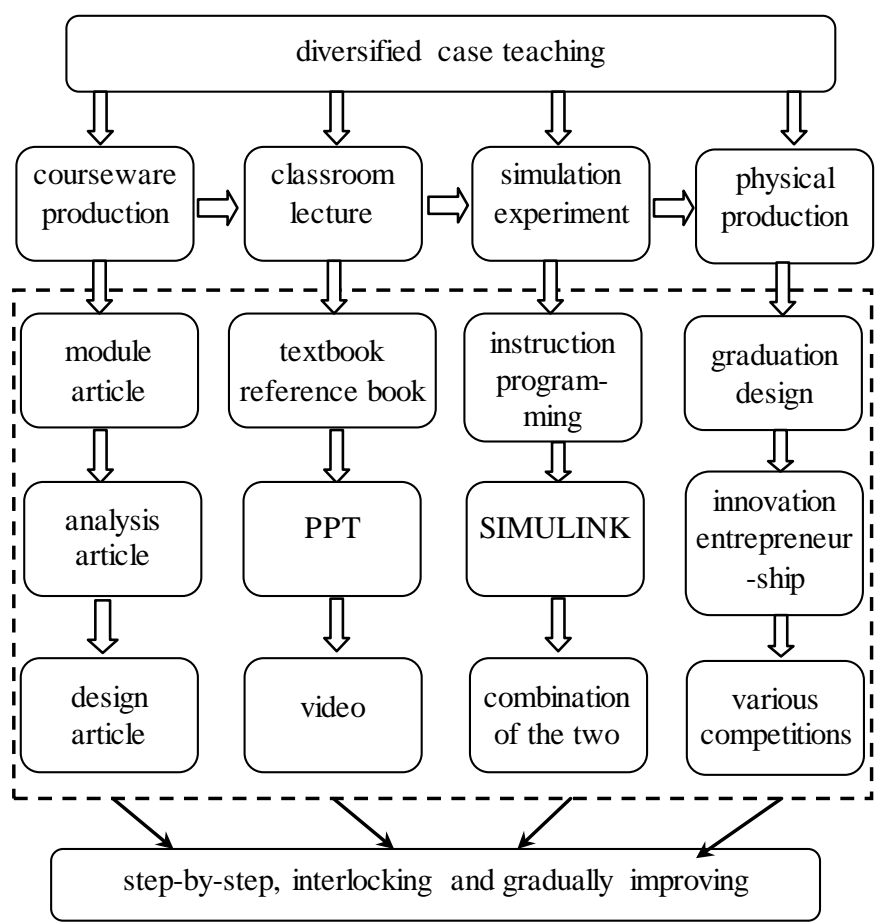

Fig. 2. Diversified case teaching measures

\section{A. Courseware Production}

Courseware production is divided into three articles: model, analysis, and design. In the model article, through the analysis of the case system, the transfer function model of each component is first obtained, and then the block diagram model of the system under different feedback conditions is obtained, and finally the mathematical model of the system is sorted out; In the analysis article, the stability, accuracy, and rapidity of the system based on the model are analyzed using methods such as time domain and frequency domain. In the design article, the requirement of system design is performed by adjusting the controller setting value through the advanced correction, lag correction, and PID correction introduced in the textbooks according to specific performance index requirements. The theoretical knowledge required in the syllabus can be modeled on the application of the case, so as to deepen students' understanding of theoretical knowledge and reach the level of proficient application.

\section{B. Classroom Lectures}

The contents and sequence of classroom lectures are basically the same as those in the textbooks. Since the derivation of mathematical models, the analysis of system performance, and the design of controllers are all applications of theoretical knowledge, the teaching of the case adopts a student-centered approach, that is, students deduce, analyze and design, which is equivalent to a comprehensive review of knowledge learning; the focus and difficulty involved in the application process can be explained by the teaching materials, PPT, and video.

\section{Simulation Experiment}

The simulation experiment introduces MATLAB instruction writing and SIMULINK model into teaching. The experiments have been developed from the demonstration of experiment box into the experiment of confirmatory, design and comprehensive, which requires the students to compile the MATLAB language program or build the SIMULINK model, debug, solve the problems through learning knowledge, so that students really act as the main body of experimental activities, fully play their creative thinking and the ability to independently analyze and solve problems. The arrangement of case content follows the principles of "combination of verification and design", "combination of design and synthesis”, and "principle-based and prominent application”.

\section{Physical Production}

There is still some difficulty in physical production relying only on the knowledge of the course. Therefore, the professional curriculum design, graduation design, college students' innovative entrepreneurial projects and various competitions are integrated into computer control technology, the principles and applications of single-chip microcomputers and other curriculum knowledge. Teaching philosophy of case teaching is truly met combining theoretical knowledge and application.

\section{IMPLEMENTATION PROCESS}

\section{A. Case Presentation and Knowledge Interpretation}

Before the explanation of theoretical knowledge, the case is presented by multimedia animation and video, and then the students are guided to think and discuss, and the knowledge points and general rules are drawn from typical cases, which makes classroom teaching neither far away from the book nor comprehend to the book, which is conducive to simplification of abstract knowledge, and encourages students to find a variety of ways to solve problems.

\section{B. Students' think and Analysis of Cases}

On the basis of cognitive theory knowledge, it fully embodies the "student-centered" teaching concept, and students play the main role, and independently analyze cases, browse textbooks, and think deeply about cases, or use control theory to analyze problems and draw their own solutions; or ask their own questions and solve the difficulties. 


\section{Exchanges in Team and Discussion of Cases}

Students are organized in small groups to discuss cases, to make full use of experimental or after-class time for case simulation, to write experimental reports, case reports or produce PPT, video reports, combining professional practice teaching, college students' innovation and entrepreneurial projects, and various competitions to create real objects.

D. Theory and Cases are Deepened by the Summary of the Teachers

Teachers evaluate the students' analysis and the discussions of design case, identify key issues, and lay a solid foundation for subsequent classroom teaching, or point out the inadequacies of students' analysis and discussion of cases, and make suggestions for their improvement. or can inspire students to sum up, so that students get more exercise; or can put forward some thought-provoking questions, prompting students to broaden their horizons, adjust their perspectives, carry out in-depth and extensive thinking, which will help students more quickly and more widely realize the migration of knowledge, capabilities and attitudes and improvement of knowledge, ability and awareness, so that new problems can be solved creatively.

\section{EFFECTIVENESS OF CASE TEACHING}

\section{A. Improve Students' Interest in Learning and Deepen Their Understanding of What They Have Learned}

The theory in the textbook is abstract and boring. If simply teaching theory and imparting knowledge is done in the classroom, it is difficult to arouse students' interest. Case teaching methods are used to explain, analyze, and discuss real and vivid cases, and the abstract theories are visualized and embodied to deepen students' perceptual knowledge. The case teaching combines the theory of books with real life, and increase the attraction of teaching content, and enable students to gain more, and gain a deep understanding of what they have learned.

\section{B. The Students' Awareness of Communication and Cooperation is Developed}

The cases are usually discussed and case reports are written in the form of small groups during case teaching. In this community of teams, each member shares a certain case task. In the process of cooperation, students truly become the main body of learning. In order to attain common goals, they work together, perform their duties, cooperate in division of labor, and respect, exchange, help and encourage each other, and show the spirit of unity and cooperation. This kind of awareness of being good at communication and cooperation has laid a solid psychological foundation for them to join in and adapt to this fierce society.

\section{The Students' Learning and Innovation Ability is Improved Significantly}

A lot of vivid and realistic cases are introduced into the classroom during t case teaching. Students will be more likely to actively think and discuss, link the theoretical knowledge with the actual situation, dare to make their own judgments and analysis, and dare to express different opinions, thus improving the depth and breadth of understanding of the knowledge also are led to some insights and deep-seated thinking in the case, as well as practical opportunities. The participation rate of students of 2014 and 2015 in the innovation and entrepreneurship project for college students is as high as $100 \%$, and the participation rate in various competitions is more than $30 \%$.

\section{CONCLUSIONS}

The introduction of case teaching of "Automatic Control Theory" in our school has developed a diversified teaching material. Through the entire teaching process, the case has been supplemented by experiments to combine theory with practice, which stimulates students' interest in learning and training. Students' awareness of communication and cooperation has been improved, and the students' ability of innovation and connection of the theory with practice has been improved, and teaching results has been achieved well.

\section{ACKNOWLEDGMENT}

This work was financially supported by the Innovation and Entrepreneurship Training Reform Model Projects of Tianjin Agricultural University (20170812), and Education and Teaching Reform Project of Tianjin Agricultural University (2016-B-08).

\section{REFERENCES}

[1] Gong Erling, Sun Zhiqiang, Shen Hui. Diversified Case-based Teaching of Automatic Control Principle[J]. Journal of EEE, 2015, 37(2):58-60.

[2] Rong Jun, Ding Yuejiao, Zhang Min,etc.. Application study of case teaching method in automatic control principle teaching[J]. Laboratory Science, 2011, 14(5): 14-16.

[3] Wang Jianan, Wang Yin, Sun Zhiyi. Application of project based teaching in the course of automatic control theory [J].Education Modernization,2017, 4(40): 251-252,268.

[4] Li Lianqi. Practice and Exploration of Cooperative Case Teaching Method Applied in Law Postgraduate Teaching[J]. Education Teaching Forum, 2018(14):186-187.

[5] Cui Hongbin, ZHAO Yuejing, LI Hongyan, Ren Youzhi, Zhang Xushe, LI Yuehua, Yang Guang. Case Teaching Method Practicing in The Process of Students Engineering Practice Ability Training[J]. Experiment Science and Technology, 2018,16(1):44-47.

[6] Li Shouke, Yu Jianda. Comparison between case teaching and traditional teaching effect[J]. New Mathematics Research,2015.7:8-9.

[7] Cai Linqin, Yu Jimin, Cen Ming, Li Yong. Practice Teaching Reform Methods for Automatic Control Principle 2013 International Conference on Education and Teaching.2013.3:98-101 